\title{
Mankind's strange love of superweapons
}

\author{
Doomsday Men: The Real Dr Strangelove \\ and the Dream of the Superweapon \\ by P. D. Smith \\ Allen Lane/Penguin: May 2007. \\ 553 pp. with index, $£ 20$ \\ St Martin's Press: December 2007. 416 pp. \\ $\$ 27.95$
}

\section{Gregg Herken}

"There is nothing in Man's industrial machinery but greed and sloth: his heart is in his weapons," said the Devil in George Bernard Shaw's Man and Superman. Shaw's adage could almost be the leitmotiv of P. D. Smith's wellresearched and altogether depressing account of humankind's long hunt for the ultimate superweapon: a doomsday device that, by its very terribleness, would make war forevermore unwinnable, and hence unthinkable. Although we all know how this tale turns out, it is a journey well worth taking. Along the way, Smith includes some fascinating asides about the men - and it was, almost exclusively, a fraternity - who, in seeking to make war obsolete, have only made it more deadly.

Typical of the breed was German chemist Fritz Haber, who invented and personally promoted the use of poison gas on First World War battlefields. As with his contemporaries in the other belligerents, Haber started out as an idealist who, once hostilities began, quickly harnessed his science in the service of the state. His motto, "Im Frieden der Menschheit, im Kriege dem Vaterland" (In peace, for mankind; in war, for the fatherland), sets a pattern followed with distressing regularity by other idealistic scientists in subsequent conflicts.

The real focus of Smith's book is Leo Szilard, a Hungarian-born American physicist who fled Nazi Germany and eventually wound up in the United States. Szilard was arguably the first to envisage how a nuclear weapon might be made. "You know what fission means," he confided to fellow physicist Edward Teller in early 1939, "it means bombs."

Ironically, it was a seemingly off-hand remark made by Szilard in a nationwide radio broadcast in February 1950 - shortly after the Truman administration announced plans to proceed to the next level of destructiveness, the hydrogen bomb - that revived interest in a true 'doomsday' weapon. Szilard envisaged building a battery of very powerful hydrogen bombs jacketed with cobalt-60, an element with a radioactive half-life of 5.7 years. In a later iteration, the bombs would be hooked up to a computer, which, on receiving a certain signal - say, a single nuclear weapon exploding on friendly territory, or the crossing of a border by enemy troops - would detonate them. Theoretically, such a device, if set off, would enshroud Earth with lingering, lethal levels of radioactivity, snuffing out all human life.

In the end, the cobalt bomb was never very

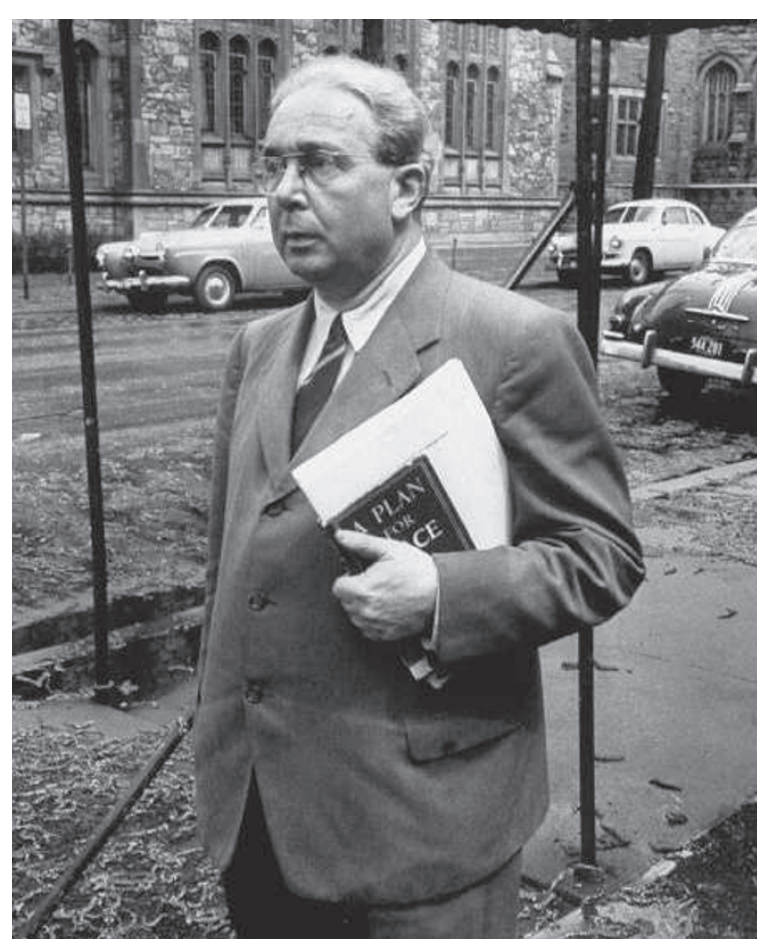

Leo Szilard was among the first to conceive of a nuclear weapon.

attractive to even the most bloody-minded of strategists because it would not have been destructive enough: the longer the half-life, the less intense the radiation. That did not stop a generation of novelists and film-makers from enlisting the cobalt bomb in their doomsday scenarios: among them, novelist Nevil Shute in On the Beach and director Stanley Kubrick in Dr. Strangelove. Nor did it prevent P. D. Smith from making the cobalt bomb the attention from the weapons that remain in the arsenals of nations, numerous, primed and waiting. Although not as deadly as Smith's fictive doomsday bomb, they are cause for us to be more fearful, for they are real. Gregg Herken is professor of history at the University of California at Merced, PO Box 2039, Merced, California 95344, USA, and author of Brotherhood of the Bomb: The Tangled Lives and Loyalties of Robert Oppenheimer, Ernest Lawrence, and Edward Teller.

\section{Linnaeus lives on}

\section{Order out of Chaos: Linnaean Plant Names and their Types \\ by $\mathrm{C}$. Jarvis \\ The Linnean Society of London: 2007. 1,016 pp. $€ 80$}

\section{Pamela S. Soltis}

The relevance of taxonomy in our genomic era is greater than ever. Correct naming is crucial for developing new foods and medicines, and for understanding our changing environment. Amazingly, we do not even know how many species of flowering plant currently exist. Estimates range from about 250,000 to more than 400,000 , and every day species are lost to human activities. Conservation, in natural habitats or botanical gardens, relies on scientific names, as does the rest of science.

Before Carl Linnaeus, species names ranged from cumbersome to unwieldy. For exam-

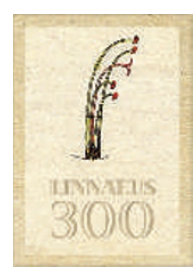

ple, Arbutus caule erecto, foliis glabris serratis, baccis polyspermis was as good as it got for 'Arbutus with upright stems, hairless, saw-toothed leaves, and many-seeded berries'. Linnaeus's binomial system of nomenclature changed all that. Species could now have a genus name plus a specific epithet. 'The father of taxonomy' applied his revolutionary system to plants in Species Plantarum, published in 1753, and to animals in the tenth edition of Systema Naturae in 1758. More than 250 years later, the name of a species remains the key that unlocks all that is known about it.

In honour of Linnaeus's 300th birthday, Charlie Jarvis's handsome new book, Order out of Chaos, gives us a glimpse into prelinnaean botany, Linnaeus's life and work, 
and the reception and impact of his ideas in eighteenth-century Europe.

Linnaeus was an avid collector and classifier of 'animals, vegetables and minerals'. He named and described his collections and the many specimens that were returned to Europe from exploration of other parts of the globe. His plant names are the starting point for valid names that follow botanical nomenclature. To be valid, a species name must be attached to one reference or 'type' specimen. This concept was implemented 150 years after Species Plantarum, so - ironically - most of the names assigned by Linnaeus himself do not have clearly associated specimens.

Enter the Linnaean Plant Name Typification Project, launched in 1981 at the London Natural History Museum to match Linnaeus's thousands of designations with the specimens and illustrations in his work. Jarvis's book chronicles this project and presents nearly 700 pages of names and their types - from Abrus precatorius L. to Zygophyllum spinosum L. Jarvis and his colleagues scoured museums and private collections to create this wonderful

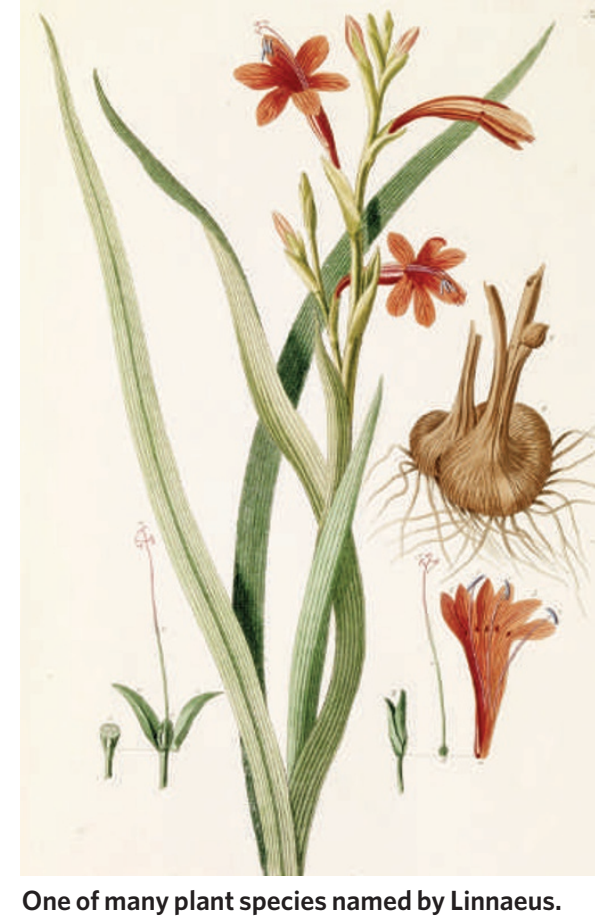

One of many plant species named by Linnaeus. reference for all those involved in taxonomy.

The book is a work of art. Even non-botanists will be seduced by this inviting package. The text is peppered with photographs and illustrations of spectacular examples of plant diversity and linnaean memorabilia. Figures range from a photograph of Linnaeus's signature and seal from 1734 , to an illustration of the wild woodland twinflower (Linnaea borealis), to Georg Dionysius Ehret's (1736) illustration of Linnaeus's 'Sexual System' of plant classification.

The appreciation for history in plant systematics is evident in this book and in the attention being paid to Linnaeus during 2007 . Even the controversy between those who favour the continued use of linnaean classification and advocates of the PhyloCode (the system that relies on evolutionary history) does not diminish Linnaeus's contribution. This book is a timely homage to linnaean names and the efforts of Jarvis's team, as systematists look for new ways to provide the richest classification systems. Pamela S. Soltis is at the Florida Museum of Natural History, University of Florida, Gainesville, Florida 32611, USA.

\section{The theatre of quantum physics}

\section{Faust in Copenhagen: A Struggle for the Soul of Physics by Gino Segrè \\ Viking/Jonathan Cape: 2007. 320 pp. $\$ 25.95 / £ 20.00$}

\section{Finn Aaserud}

The year 1932 was a particularly eventful one in physics. In Faust in Copenhagen, the physicist Gino Segrè chooses as his point of departure an annual meeting held in April of that year at Niels Bohr's Institute for Theoretical Physics at the University of Copenhagen, Denmark. In Segrè's view, the 1932 gathering symbolized the end of the political neutrality of physics and physicists, coinciding as it did with the arrival of Hitler and crucial discoveries in nuclear physics that would make possible the subsequent development of the atomic bomb.

Segrè introduces us at the outset to seven physicists who attended this series of informal but prestigious meetings: Niels Bohr, Paul Dirac, Werner Heisenberg, Paul Ehrenfest, Max Delbrück, Lise Meitner and Wolfgang Pauli. He presents a fascinating comparison of these main characters in the first hundred pages, and then launches into a spirited and engaging history of the development of quantum physics from about 1900 to 1932. Segrès emphasis is always on the human aspect, and he is unable in this part of the book to limit his story to the seven physicists whom he claims the book is about. Towards the end, he returns to the original group, vividly describing their subsequent careers, again with illuminating comparisons. As the nephew of Emilio Segrè, a Nobel prize-winning physicist trained by some of the main characters in the book, Segrè deploys his background effectively for dramatic and comparative purposes. This, however, shortens his distance from the subject matter - for example, the role of experimental physics at Bohr's institute is underplayed. Moreover, he seemingly contradicts his interpretation of the 1932 meeting as the end of the political neutrality of physics, by praising his own field for continuing to this day in the disinterested tradition instigated by Bohr.

Bohr's crucial contributions to quantum mechanics, Segrè writes, were "largely ignored" by Segrès own generation of physicists, and he seems intent on rectifying the situation. Whether or not this is necessary, Segrè's approach reveals important insight into Bohr as a person as well as into his interaction with and importance for physicists who followed him.

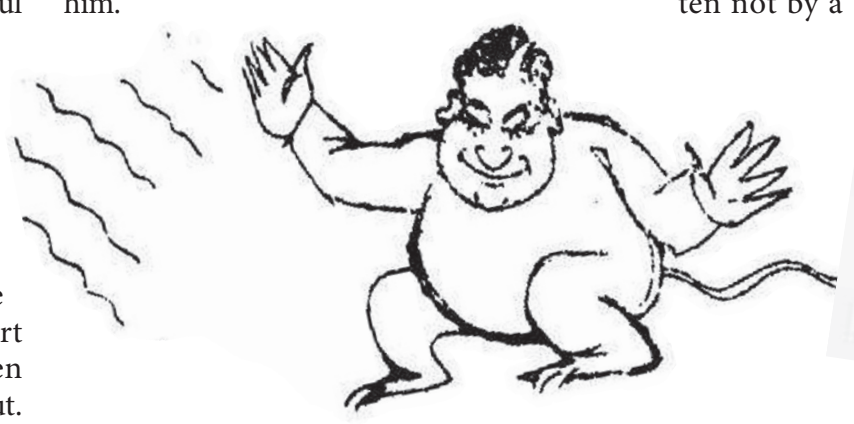

At the end of the 1932 meeting, in celebration of the hundredth anniversary of Johann Wolfgang von Goethe's death, some of the younger scientists performed a parody of Faust, replacing Goethe's original characters with some of the main theoretical physicists of the day, most of whom were also assembled in Copenhagen: Niels Bohr was portrayed as God, Wolfgang Pauli as the Devil and Paul Ehrenfest as Faust. The parody described the state of physics at the time, and Segrè regards it as sufficiently important to name his book after it.

At least to me, however, Segrè does not integrate the play into his narrative satisfactorily. The worldwide success of Michael Frayn's play Copenhagen, first set up in London in 1998, inspired a still-active interest in the relationship between science and the theatre. Frayn's play even shares two of Segrès main characters - Niels Bohr and Werner Heisenberg. But Faust as enacted at the 1932 meeting was written not by a

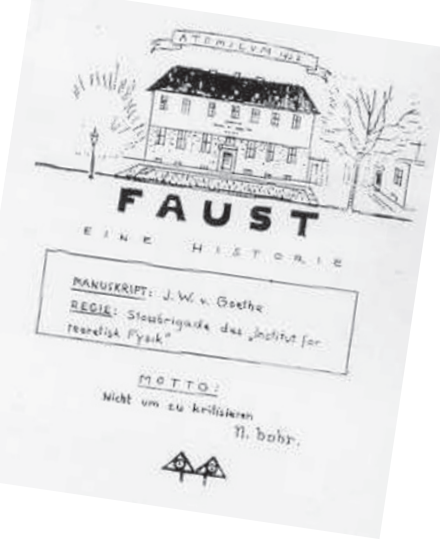

Wolfgang Pauli as the Devil in a parody of Faust, performed by physicists at a meeting in 1932. 